\title{
The Views of Teacher Candidates on Using Cloud Technologies in Education
}

\author{
Agah Tuğrul Korucu ${ }^{1}, \mathrm{PhD}$ \\ ${ }^{1}$ Assistant Professor Doctor, Department of Computer Education and Instructional Technology, Ahmet Kelesoglu \\ Faculty of Education, Necmettin Erbakan University, Konya, TURKEY \\ Correspondence: Agah Tuğrul Korucu, PhD, Department of Computer Education and Instructional Technology, \\ Ahmet Kelesoglu Faculty of Education, Necmettin Erbakan University, Konya, TURKEY. E-mail: \\ agah.korucu@gmail.com
}

Received: November 2, 2016

Accepted: November 17, 2016 Online Published: November 22, 2016

doi:10.5430/ijhe.v6n1p84

URL: http://dx.doi.org/10.5430/ijhe.v6n1p84

\begin{abstract}
This study aims to describe the views of student IT teachers' and the factors which affect their priorities to use cloud services progressively. The study is conducted by qualitative research approach. The data obtained from the department of Computer Education and Instructional Technology students are collected by structured form for the use of cloud technologies. The data is analyzed by content analysis method. According to the findings, student teachers use cloud systems for file sharing and they do not use cloud systems because they do not need them or they do not know them mostly; cloud systems' main advantage is the flexibility of use independence from time and space and their main disadvantage are the security issues and the fact that they rely on the internet connection; cloud systems' main benefits for educational purposes are the flexibility and cost of use, and the fact that they support connection and collaboration between different users; participants think cloud services may have benefits on personal development of individuals' information literacy knowledge and can improve teaching skills and on connection and collaborative work with various people and finally student teachers are in the opinion that cloud services are more appropriate for application-project courses and both group and individuals' instruction. Due to cloud services' benefits on education, adopting them into education system is important to reach the developed education level. Therefore, teachers should be trained among those innovative technologies by IT teachers who are the core element for this process.
\end{abstract}

Keywords: Cloud services, Teacher candidates, Cloud technologies, ICT Integration, Instructional technology

\section{Introduction}

Cloud services which are one of the Web 2.0 technologies, are the general name of the services provided through cloud computing and enable the fact that different users can access the same application or document via The Internet (Furht, B., \& Escalante, A. 2010). Since this process works on a server rather than user's computer, aged computers can remain valuable for longer. Furthermore, installing software or resolving the issues can be done by server (e.g. School's central computer), which leads to spending less time in contrast to individual PC in this manner (Tara S. Behrend, Eric N. Wiebe, Jennifer E. London \& Emily C. Johnson, 2011). These features make cloud services suitable for use in the teaching and learning process (Denton, D. W. 2012). The most widely used cloud services for educational purposes are those accessed via web browsers and they store data and application together, which allows users to share data (e.g. Dropbox) and adjust it collaboratively (e.g. GoogleDocs) (Sclater, N. 2012).

Cloud systems considered as an innovative technology which supports teacher development, student development as both collaboratively and individually and school development due to its economic structure. Although the "cloud" term is not being used frequently in Turkey, it has a common use in the world with different purposes. In some parts of the world, such as Africa and Asia, since cloud computing promises cost efficiency, acceleration in the learning process and privacy concern cloud computing is emerging as an empowering tool that is being used to advance the cause of education especially in low budget countries (Sultan, N. 2010) (Bouyer, A., \& Arasteh, B. 2014). Supporting this information, researchers found that using cloud services as an educational tool is an efficient way to meet the needs in the current economic status (Al Noor, S., Mustafa, G., Chowdhury, S. A., Hossain, M. Z., \& Jaigirdar, F. T. 2010). Applying Cloud Computing in education both diminishes the burden of handling the complex IT infrastructure management and maintenance from educational institutions and provides financial relief (Chandra, 
D. G., \& Borah, M. D. 2012). Cloud based education has serious positive impacts on the development of the students, staff, trainers and institutions and also it provides significant advantage for low-income students from rural areas participating in distance education integrated cloud services (Rao, N. M., Sasidhar, C., \& Kumar, V. S. 2012). Distance education can be a solution in the situations in which teachers cannot meet the needs of students. In China, cloud computing provides balance between the number of students and teachers since the collaborative learning appears in such environments, which relieves the burden on teachers (Liao, J., Wang, M., Ran, W., \& Yang, S. J. 2014). Furthermore, distance education system based on cloud computing can aid higher education students to learn in an independent, quick and collaborative way (Zhao, H. Y., Zhang, P., Zhang, H., \& Zhang, X. Y. 2014). Moreover, researchers have indicated that a virtual environment built in cloud computing can be used in education and also this environment can help teachers explore and share new ideas with respect to designing, modifying and monitoring educational or course contents (Al-Zoube, M., Abou El-Seoud, S., \& Wyne, M. F. 2010). These demonstrate cloud based systems improve teaching and learning equally and they can boost the creative thinking for students and teachers. When considering literature, it is seen that in the studies researched with regard to cloud systems in education concern forming an environment based on cloud computing and the students' perceptions towards cloud systems in Turkey. A study consisting of Office.com Google Docs demonstrates that the sustainability of the personal learning environment is supported by cloud services (Mutlu, A. P. 2015). Another study revealed that cloud computing is beneficial for cost, convenient and supports collaboration and effective communication among students (Piotrowski, D. M. 2013). In addition, the students in Turkey are aware of cloud services and they have been using them for other purposes. However students are uncertain about usage of Google Drive with regard to assignment submission and about their positive attitude of the course. It is also revealed that cloud based education can decrease the problems arising from distribution, collection and archiving of assignments (Özdemir, O., \& Erdemci H. 2014). Compared with those in the other part of the world, the situation in Turkey is unstable. The reason for this may be insufficient knowledge of IT teachers about using cloud systems since the implementation of cloud systems in education depends on IT teachers first. IT teachers are the ones who encourage the other teachers and the students to learn new technology and integrate it into teaching-learning process. Therefore, this paper aims to describe the perceptions of IT teacher candidates' and the factors affect their priorities to use cloud services progressively. Also, the main research question of this study is; "What are the views of IT teacher candidates' and the factors affecting their priorities to use cloud services progressively?" Within the framework of this main research question, the answers to the following questions are sought;

In order to present this aim, answers have been sought for the following research questions;

1. Do you use cloud services? Did you ever use cloud services in any lecture for educational purposes?

2. What are the strengths and weaknesses of cloud services in education?

3. What could be the benefits of using cloud services for educational purposes?

4. Are you using cloud systems for the management of classroom applications and activities, or for daily interactions?

5. Are there any limitations of the use of cloud services in education?"

6. Do you use cloud services in your professional life? What could be the benefits in terms of students?

7. What type of benefits the use of cloud services brings to you as a teacher candidate?

8. What could be the benefits of using cloud services in terms of students?

9. In your opinion, what are the most appropriate course and subject for the use of cloud services? A. can it be used in individual or group instruction? B. is it appropriate for large populated classes?

\section{Methods}

\subsection{Research Model and Study Group}

Qualitative research approach is used in order to respond research questions. The main advantage of the studies in which the qualitative research approach is used is doing a depth inquiry about one or more attributes, case or features. In other words, qualitative approach is interrogating with an overview all the components or reasons (technology, environment, student, teacher, case, process, etc.) and determining how they affect and are affected by the present situation. In general, it is a research method which allows in-depth examination a phenomenon or an event which is not controlled by the researchers based on questions such as "how?" and "why?" (Şimşek, H., \& Yıldırım, A. 2011). In this paper, the aim for using qualitative research method is to reveal examined subject in a detailed and realistic way. Therefore, it is important to analyze the data in detail, directly with the support of expressions of study group as 
much as possible. The purpose of qualitative approach is to analyze the relevance between gathered data and theory put forward and also the effect of the learning outcomes. (Creswell, J. W. \& Plano-Clark, V. L. 2007)(Miles, M. B. \& Huberman, A. M. 1994)(Strauss, A. L., \&Corbin, J. 1998)

Table 1 includes the demographical data belonging to teacher candidates of the study group.

Table 1. Demographical data of participants

\begin{tabular}{llll}
\hline & & $N$ & $\%$ \\
\hline \multirow{3}{*}{ Gender } & Female & 65 & 52,8 \\
& Male & 58 & 47,2 \\
& Total & 123 & 100,0 \\
& $1^{\text {st }}$ grade & 26 & 21,1 \\
Grade Level & $2^{\text {nd }}$ grade & 31 & 25,2 \\
& $3^{\text {rd }}$ grade & 34 & 27,6 \\
& $4^{\text {th }}$ grade & 32 & 26,0 \\
& Total & 123 & 100,0 \\
\hline
\end{tabular}

As it is clear in Table 1, among 123 students, $58(47,2 \%)$ are male and $65(52,8 \%)$ are female.

In addition, among 123 students, $26(21,1 \%)$, are in $1^{\text {st }}$ grade, $31(25,2 \%)$ are in $2^{\text {nd }}$ grade, $34(27,6 \%)$ are in $3^{\text {rd }}$ grade and $32(26,0 \%)$ are in $4^{\text {th }}$ grade.

\subsection{Data Collection Tools}

The structured form for the use of cloud technologies is developed by researchers and includes 11 open-ended questions. The structured form is revised by 5 field experts and 2 language experts and it is formed in its final structure including 9 open-ended questions.

\subsection{Data Analysis}

Obtained data through the qualitative analysis is analyzed by content analysis method. In content analysis method, study group's responses to data collection instruments are classified as category, theme and code and their frequencies are determined and the results are interpreted by an expert view. Revised by 3 specialists and 1 linguist, the form was finalized as 9 open-ended questions and the coding scheme. Additionally, student teachers' views which support intensive codes are added for every question (Şimşek, H., \& Yıldırım, A. 2011).

In content analysis, there are four stages which are processing and coding data obtained through data collection instruments, finding themes, organization of codes and themes, identification and interpretation of the findings (Şimşek, H., \& Yıldırım, A. 2011), (Büyüköztürk, Ş., Kılıç-Çakmak, E., Akgün, Ö. E., Karadeniz, Ş. \& Demirel, F. 2013). In this study, after coding the data several themes are obtained and data are organized, grouped according to themes and findings are presented by converting data into numerical values and suggestions are offered. In addition, 1-2 responses given for each question are written as supporting the findings. In the study, student teachers' names are not given. Instead, $\mathrm{K}-1, \mathrm{~K}-2 \ldots \mathrm{K}-123$ codes are used in the findings part of the research. As a result of the analysis, strongly similarity was found between the coding made by 3 field experts and the coding made by the researcher.

\section{Results}

\subsection{The Findings Related to the $1^{\text {st }}$ Research Question}

The codes developed by the answers given by teacher candidates are divided into 3 categories for the 1 st research question: "Do you use cloud services? Did you ever use cloud services in any lecture for educational purposes?" 
Table 2. Using purposes of cloud services

\begin{tabular}{|c|c|c|c|}
\hline \multirow{2}{*}{ Category } & \multirow{2}{*}{ Main Theme } & \multicolumn{2}{|c|}{ Codes } \\
\hline & & Positive & Negative \\
\hline \multirow{5}{*}{ Personal } & Need (p) & 4 & 7 \\
\hline & Knowledge (p) & - & 7 \\
\hline & Access (p) & 5 & - \\
\hline & Storage (p) & 5 & - \\
\hline & Sharing (p) & 12 & - \\
\hline \multirow{2}{*}{ Technical } & Security (t) & - & 3 \\
\hline & Internet $(\mathrm{t})$ & - & 2 \\
\hline \multirow{3}{*}{ Educational } & Assignments (e) & 8 & - \\
\hline & Lecture Notes (e) & 3 & - \\
\hline & Collaboration (e) & 6 & - \\
\hline
\end{tabular}

These categories are analyzed according to "positive and negative" aspects and frequencies are given in Table 2. Categories are introduced as personal, technical and educational. The answers given by teacher candidates are stated numerically with the help of main and sub themes.

In the category of personal, 'need' code determines the state of necessity for cloud service use; the 'knowledge' code determines the knowledge about cloud services; the 'access' code determines the accessing data via cloud services; The 'storage' code determines data storage via cloud services; the 'sharing' code determines data sharing on cloud services. The positive aspects are determined as " $n=4$ " for need, " $n=5$ " for access, " $n=5$ " for storage, " $n=12$ " for sharing; the negative aspects are determined as " $\mathrm{n}=7$ " for need, " $\mathrm{n}=7$ " for knowledge. In the category of personal, the answers supporting the results are like the following;

" $\mathrm{K} 1$; Generally I prefer these systems for file sharing. In fact, I don't have any idea about using these systems on the purpose of education."

"K26; I don't use cloud systems and I don't have any account because I haven't needed those systems up to present."

In the category of technical, the 'security' code determines the safety and privacy of uploaded data; the 'internet' code determines the presence of internet connection. In the technical category, the negative aspects are determined as " $\mathrm{n}=3$ " for security, " $\mathrm{n}=2$ for internet, in the technical category, the answers supporting the results are like the following;

"K67; security issues are the main concerns which doubt me about using cloud systems. That's why I don't use those systems."

In the educational category, the 'assignment' code determines submission the assignment via cloud services; the 'lecture notes' code determines the use of cloud services to share lecture notes with students; the 'collaboration' code determines the collaborative work among cloud services. The positive aspects are determined as " $n=8$ " for assignment " $n=3$ " for lecture notes, " $n=6$ " for collaborative. In the category of educational, the answers supporting the results are like the following;

"K78; we used Easy Class in our lecture. We shared information about the course and assignments on Easy Class."

\subsection{The Findings Related to the $2^{\text {nd }}$ Research Question}

The codes developed by the answers given by teacher candidates are divided into 3 categories for the 2nd research question: "What are the strengths and weaknesses of cloud services in education?" 
Table 3. Strengths and weaknesses of cloud services

\begin{tabular}{llll}
\hline \multirow{2}{*}{ Category } & Main Theme & \multicolumn{2}{c}{ Podes } \\
& Responsibility (p) & 2 & Negative \\
\hline \multirow{3}{*}{ Personal } & Communication (p) & 2 & - \\
& Knowledge (p) & - & 4 \\
& Flexibility (t) & 40 & - \\
& Time (t) & 13 & - \\
Technical & Space (t) & 11 & 3 \\
& Connection (t) & 11 & - \\
& Security (t) & - & 19 \\
& Internet (t) & - & 18 \\
& System (t) & - & 9 \\
& Cost (t) & 8 & 1 \\
& Usability (t) & 5 & - \\
Collaboration (e) & 6 & 1 \\
& Feedback (e) & 1 & 2 \\
& Participation (e) & 4 & - \\
\hline
\end{tabular}

These categories are analyzed according to "positive and negative" aspects and frequencies are given in Table 3. Categories are introduced as personal, technical and educational. The answers given by teacher candidates are stated numerically with the help of main and sub themes.

In the category of personal, 'responsibility' code determines the state of responsibility among individuals in the use of cloud services; the 'communication' code determines the communication via cloud services; the 'knowledge' code determines the knowledge about cloud services. In the personal category, the positive aspects are determined as " $n=2$ " for responsibility, " $\mathrm{n}=2$ " for communication; the negative aspects are determined as " $\mathrm{n}=5$ " for communication, " $\mathrm{n}=4$ " for knowledge. In the category of personal, the answers supporting the results are like the following;

"K69; in my opinion, the strengths of cloud systems are to have the opportunity to communicate the lecturer instantly and getting feedback in any point.

In the category of technical, the 'flexibility' code determines the independency of cloud services from time, space and material; the 'time' code determines the time used on works done by cloud services; the 'space' code determines the data management systems supported by cloud services; the 'connection' code determines the connection individuals to the same space synchronize or desynchronize; the 'security' code determines the safety and privacy of data in cloud services ; the 'internet' code determines the quality of internet connection ; the 'system' code determines the systematic features working background which cannot be interfered by users; the 'cost' code determines the financial status of cloud services and the 'usability' code determines the quality of cloud services' user interface. In the technical category, the positive aspects are determined as " $\mathrm{n}=40$ " for flexibility, " $\mathrm{n}=13$ " for time, " $\mathrm{n}=11$ " for space, " $\mathrm{n}=11$ " for connection, " $\mathrm{n}=8$ " for cost, " $\mathrm{n}=5$ " for usability, the negative aspects are determined as " $n=3$ " for space, " $n=19$ " for security, " $n=18$ " for internet, " $n=9$ " for system, " $n=1$ " for cost. In the technical category, the answers supporting the results are like the following;

"K4; the data Exchange rate alters depending on the Internet speed which means the less internet speed the less exchange rate. Another weakness of cloud systems which concerns everybody is the security issues. There is a possibility that malicious people can seize the data saved in virtual servers."

In the educational category, the 'collaborative' code determines collaborative learning in groups; the 'feedback' code determines the use of cloud services to prepare for course subject before the lesson; the 'active participation' code 
determines the status of active participation among cloud service used courses; the 'control' code determines teachers' control over the classroom; the 'independence' code determines the individual learning without need of anyone. The positive aspects are determined as " $n=6$ " for collaborative " $n=1$ " for feedback, " $n=4$ " for active participation, " $\mathrm{n}=2$ " for independence. In the category of educational, the answers supporting the results are like the following;

"K89; the advantage of using cloud in education is the active participation of students in the classroom in the virtual environments provided by the cloud technology. Therefore it improves the consciousness of responsibility."

\subsection{The Findings Related to the $3^{\text {rd }}$ Research Question}

The codes developed by the answers given by teacher candidates are divided into 3 categories for the 3rd research question: "What could be the benefits of using cloud services for educational purposes?"

Table 4. Benefits of using cloud services for educational purposes

\begin{tabular}{lll}
\hline Category & Main Theme & Codes \\
& Flexibility (t) & Positive \\
\hline & Time (t) & 41 \\
Space (t) & 10 \\
Technical & Connection (t) & 10 \\
& Security (t) & 14 \\
Application (t) & 9 \\
Cost (t) & 1 \\
& Usability (t) & 12 \\
& Performance (t) & 3 \\
Collaboration (e) & 3 \\
Learning (e) & 10 \\
Participation (e) & 8 \\
Motivation (e) & 1 \\
Independency (e) & 4 \\
& Responsibility (e) & 2 \\
& Communication (e) & 1 \\
Information Literacy (e) & 7 \\
& & 1
\end{tabular}

These categories are analyzed according to "positive" aspects and frequencies are given in Table 4. The categories are introduced as technical and educational. The answers given by teacher candidates are stated numerically with the help of main and sub themes.

In the category of technical, the 'flexibility' code determines the independency of cloud services from time, space and material; the 'time' code determines the time used for works done by cloud services; the 'space' code determines the data management systems supported by cloud services; the 'connection' code determines the connection individuals to the same space synchronize or desynchronize; the 'security' code determines the safety and privacy of data in cloud services ; the 'application' code determines the usage of cloud services as application; the 'cost' code determines the financial status of cloud services and the 'usability' code determines the quality of cloud services' user interface; the 'performance' code determines the systematic features working background which cannot be interfered by users. In the technical category, the positive aspects are determined as " $n=41$ " for flexibility, " $n=10$ " for time, " $\mathrm{n}=10$ " for space, " $\mathrm{n}=14$ " for connection, " $\mathrm{n}=9$ " for security, " $\mathrm{n}=1$ "for application, " $\mathrm{n}=12$ " for cost, " $\mathrm{n}=3$ " for usability, " $n=3$ " for performance". In the technical category, the answers supporting the results are like the following; 
"K56; it is really useful in sharing data, assignment, Project and information and sending files. It is a useful platform for both students and teachers. It facilitates studying, it saves time."

In the educational category, the 'collaborative' code determines collaborative learning in groups; the 'learning' code determines the effect of cloud services on learning; the 'active participation' code determines the status of active participation among cloud service used courses; the 'motivation' code determines students' motivation for courses; the 'independence' code determines the individual learning without need of anyone; the 'responsibility' code determines students' responsibility with regard to course subjects; the 'communication' code determines the communication via cloud services; the 'information literacy' code determines information literacy status of students. The positive aspects are determined as " $\mathrm{n}=10$ " for collaborative " $\mathrm{n}=8$ " for learning, " $\mathrm{n}=1$ " for active participation, " $\mathrm{n}=4$ " for motivation, " $\mathrm{n}=2$ " for independence " $\mathrm{n}=1$ " for responsibility, " $\mathrm{n}=7$ " for communication, " $\mathrm{n}=1$ " for active participation. In the category of educational, the answers supporting the results are like the following;

"K4; especially distance education, mobile learning, collaborative learning are supported by cloud systems. We can motivate our students via using these technologies."

\subsection{The Findings Related to the $4^{\text {th }}$ Research Question}

The codes developed by the answers given by teacher candidates are divided into 2 categories for the 4th research question: "Are you using cloud systems for the management of classroom applications and activities, or for daily interactions?"

Table 5. Benefits of using cloud services for educational purposes

\begin{tabular}{llll}
\hline \multirow{2}{*}{ Category } & Main Theme & \multicolumn{2}{c}{ Codes } \\
& Lecture Notes (s) & Daily & Educational \\
\hline & Assignments (s) & - & 18 \\
& Document Files (s) & 32 & - \\
Storage/Sharing & Music Files (s) & 9 & - \\
& Video Files (s) & 14 & - \\
& Image Files (s) & 25 & - \\
& Applications (s) & 11 & - \\
& Announcements (c) & - & 16 \\
Communication & Interaction (c) & 36 & 19 \\
& Assistance (c) & - & 12 \\
\hline
\end{tabular}

These categories are analyzed according to "daily and education" aspects and frequencies are given in Table 5. Categories are introduced as storage/sharing and communication. The answers given by teacher candidates are stated numerically with the help of main and sub themes.

In the category of storage/sharing, the 'lecture notes' code determines the lecture notes sharing via cloud services between student-student and teacher-student; the 'assignment' code determines the assignment submission via cloud services; the 'document' code determines storage and sharing office documents via cloud services; the 'music' code determines the stored music files; the 'video' code is determines stored video files; the 'application' code determines the stored applications such as games. In the storage/sharing category, the daily aspects are determined as " $\mathrm{n}=32$ " for document, " $\mathrm{n}=9$ " for music, " $\mathrm{n}=14$ " for video, " $\mathrm{n}=25$ " for image, " $\mathrm{n}=11$ " for application; the educational aspects are determined as " $\mathrm{n}=18$ " for lecture notes, " $\mathrm{n}=13$ " for assignment. In the category of storage/sharing, the answers supporting the results are like the following;

"K113; ...I use it for daily interaction usually. For example, to stay in touch with my friends, sending files or sharing photos."

In the category of communication, 'announcements' code determines to announce educational news; the 'interaction' code determines the interaction between individuals in daily and educational life; the 'assistance' code determines to get help from friends about a course subject. In the category of communication, the daily aspects are determined as 
" $\mathrm{n}=36$ " for interaction; the educational aspects are determined as " $\mathrm{n}=16$ " for announcements, " $\mathrm{n}=19$ " for interaction, " $\mathrm{n}=12$ " for assistance. In the category of communication, the answers supporting the results are like the following;

"K22; I use cloud Technologies in order to share data with my friends, to be in interaction with them, working collaboratively, creating a communication environment, reaching the up-to-date knowledge."

\subsection{The Findings Related to the $5^{\text {th }}$ Research Question}

The codes developed by the answers given by teacher candidates are divided into 3 categories for the 5 th research question: "Are there any limitations of the use of cloud services in education?"

Table 6. Limitations of the use of cloud services in education

\begin{tabular}{lll}
\hline Category & Main Theme & Codes \\
& Affective (ped.) & Negative \\
\hline \multirow{3}{*}{ Pedagogical } & Distraction (ped.) & 12 \\
& Learning (ped.) & 12 \\
& Psychomotor (ped.) & 14 \\
Communication (per.) & 17 \\
Personal & Information Literacy & 12 \\
& (per.) & 21 \\
& Recognition (per.) & 12 \\
& Responsibility (per.) & 15 \\
Compatibility (t) & 12 \\
& Cost (t) & 14 \\
& Hardware/Software (t) & 48 \\
& Internet Connection (t) & 16 \\
& Limit (t) & 14 \\
& Security (t) & 20 \\
& System (t) & 15 \\
& Usability (t) & 15
\end{tabular}

These categories are analyzed according to "negative" aspects and frequencies are given in Table 6. The category is introduced as pedagogical, personal and technical. The answers given by teacher candidates are stated numerically with the help of codes.

The 'technical' code determines the limitations of cloud services with regards to technical features; the 'personal' code determines the limitations of cloud services with regard to personal features and the 'pedagogical' code determines the limitations of cloud services with regard to pedagogical features in main themes. In the technical main theme; the 'cost' code determines the financial status of cloud services; the 'limit' code determines the limit for the data storage on cloud services; the 'internet connection' code determines the quality of internet connection; the 'hardware/ software' code determines the quality of hardware and software; the 'security' code determines the safety and privacy of data in cloud services; the 'usability' code determines the quality of cloud services' user interface; the 'compatibility' code determines the compatibility between applications and cloud service and the 'system' code determines the systematic features working background which cannot be interfered. In the technical main theme, the negative aspects are determined as " $\mathrm{n}=12$ " for cost, " $\mathrm{n}=16$ " for limit, " $\mathrm{n}=48$ " for internet connection, " $\mathrm{n}=14$ " for hardware/software, " $\mathrm{n}=14$ " for security, " $\mathrm{n}=15$ " for usability, " $\mathrm{n}=15$ " for compatibility, " $\mathrm{n}=20$ " for system. In the technical main theme, the answers supporting the results are like the following;

"K89; there are security problems because the control does not belong to the user. Moreover, availability of internet connection or the low internet speed can cause to lose the link with desired files."

In the personal main theme, 'recognition' code determines the information about cloud services; the 'communication' code determines social communication skills; the 'information literacy' determines the status of information literacy; 
the 'responsibility' code determines the status of responsibility for students and these are explained by content analysis. The negative aspects are determined as " $n=21$ " for recognition, " $n=17$ " for communication, " $n=12$ " for information literacy, and " $n=12$ " for responsibility. In the main theme of personal, the answers supporting the results are like the following;

"K116; ... it cannot replace the face-to-face communication, so there can be communication problems because of the internet limitation."

In the pedagogical main theme, the 'psychomotor' code determines the effect of cloud services on psychomotor skills; the 'affective' code determines the effect of cloud services on affective domain; the 'learning' code determines the effects of cloud services on learning concepts; the 'distraction' code determines the situation of distractions on cloud environment; and these are explained by content analysis. The negative aspects are determined as " $\mathrm{n}=14$ " for psychomotor, " $\mathrm{n}=12$ " for affective, " $\mathrm{n}=15$ " for learning, " $\mathrm{n}=12$ " for distraction. In the main theme of pedagogical, the answers supporting the results are like the following;

"K2; cloud systems are effective in the development of cognitive domain. However they are not effective in the development of affective and psychomotor behaviors."

\subsection{The Findings Related to the $6^{\text {th }}$ Research Question}

The codes developed by the answers given by teacher candidates are divided into 2 categories for the 6th research question: "Do you use cloud services in your professional life? What could be the benefits in terms of students?"

Table 7. Benefits of cloud services for professional life in education

\begin{tabular}{|c|c|c|}
\hline \multirow{2}{*}{ Category } & \multirow{2}{*}{ Main Theme } & Codes \\
\hline & & Positive \\
\hline \multirow{10}{*}{ Pedagogical } & Collaboration (p) & 8 \\
\hline & Communication (p) & 17 \\
\hline & $\begin{array}{l}\text { Information Literacy } \\
\text { (p) }\end{array}$ & 12 \\
\hline & Inquiry (p) & 2 \\
\hline & Learning (p) & 5 \\
\hline & Make up (p) & 2 \\
\hline & Motivation (p) & 7 \\
\hline & Participation (p) & 10 \\
\hline & Preparation (p) & 1 \\
\hline & Responsibility (p) & 1 \\
\hline \multirow{9}{*}{ Technical } & Compatibility (t) & 1 \\
\hline & Connection (t) & 21 \\
\hline & Cost (t) & 5 \\
\hline & Flexibility (t) & 30 \\
\hline & Performance (t) & 2 \\
\hline & Provided Space (t) & 9 \\
\hline & Security (t) & 3 \\
\hline & Time $(\mathrm{t})$ & 4 \\
\hline & Usability (t) & 6 \\
\hline
\end{tabular}

These categories are analyzed according to "positive" aspects and frequencies are given in Table 7. The categories are introduced as technical and pedagogical. The answers given by teacher candidates are stated numerically with the help of main and sub themes. 
The 'technical' code determines the benefits of cloud services with regard to technical features; the 'pedagogical' code determines the benefits of cloud services with regard to pedagogical features. In the technical category, the 'cost' code determines the financial status of cloud services; the 'flexibility' code determines the independency of cloud services from time, space and material; the 'time' code determines the time use of works done by cloud services; the 'provided space' code determines the data management systems supported by cloud services; the 'connection' code determines the connection individuals to the same space synchronize or desynchronize; the 'usability' code determines the usability of cloud service's interface, the 'performance' code determines technical performance of cloud service's mainframes; the 'security' code determines the safety of the data; the 'compatibility' code determines the compatibility among software applications used in cloud services. The positive aspects are determined as " $\mathrm{n}=5$ " for cost, " $\mathrm{n}=30$ " for flexibility, " $\mathrm{n}=4$ for transaction speed, " $\mathrm{n}=9$ " for provided space, " $\mathrm{n}=21$ " for connection, " $n=6$ " for usability, " $n=2$ " for performance, " $n=3$ for security, " $n=1$ " for compatibility. In the technical category, the answers supporting the results are like the following;

"K78; ...students can reach the knowledge quickly. Students and teachers can work at the same assignments or group projects synchronously. Moreover they can share the knowledge via Office Program which means they can view their work on the browser without the need of any other software."

In the pedagogical main theme, the 'makeup' code determines the chance of making up for missed classes; the 'preparation' code determines the use of cloud services to prepare for course subject before the lesson; the 'communication' code determines the student-student teacher-student communication in educational cloud environment; the 'collaborative' code determines collaborative learning in groups; the 'learning' code determines the effect of cloud services on learning; the 'motivation' code determines the students' motivation among cloud service used courses; the 'inquiry' code determines the encouragement of cloud services to research; the 'information literacy' code determines the effect of cloud services on information literacy; the 'active participation' code determines the status of active participation among cloud service used courses and 'responsibility' code determines students' responsibility among lectures and these are explained by content analysis. The positive aspects are determined as " $\mathrm{n}=2$ " for makeup, " $\mathrm{n}=1$ " for preparation, " $\mathrm{n}=17$ " for communication, " $\mathrm{n}=8$ " for collaborative, " $\mathrm{n}=5$ " for learning, " $\mathrm{n}=7$ " for motivation, " $\mathrm{n}=2$ " for inquiry, " $\mathrm{n}=12$ " for information literacy " $\mathrm{n}=10$ " for active participation, " $\mathrm{n}=1$ " for responsibility. In the category of pedagogical, the answers supporting the results are like the following;

"K17; Yes, I'd like to use them in order to guide students to study, provide students' active participation and make them use the technology."

\subsection{The Findings Related to the $7^{\text {th }}$ Research Question}

The codes developed by the answers given by teacher candidates are divided into 2 categories for the 7th research question: "What type of benefits the use of cloud services brings to you as a teacher candidate?"

Table 8. Benefits of cloud services for teachers

\begin{tabular}{lll}
\hline \multirow{2}{*}{ Category } & Main Theme & $\begin{array}{l}\text { Codes } \\
\text { Positive }\end{array}$ \\
\hline \multirow{3}{*}{ Personal } & Flexibility (per.) & 32 \\
& Information Literacy (per.) & 46 \\
& Security (per.) & 20 \\
& Speed (per.) & 17 \\
\multirow{3}{*}{ Professional } & Storage (per.) & 34 \\
& Interaction (pro.) & 37 \\
& Research Skills (pro.) & 23 \\
& Teaching Skills (pro.) & 40
\end{tabular}

These categories are analyzed according to "positive" aspects and frequencies are given in Table 8. The category is introduced as personal and professional. The answers given by teacher candidates are stated numerically with the help of codes.

The 'personal' code determines teachers' benefits of cloud services with regard to personal aspect; the 'professional' code determines teachers' benefits of cloud services with regard to professional aspect in main themes. In the 
personal main theme, the 'security' code determines the safety and privacy of data in cloud services; the 'flexibility' code determines the independency of cloud services from time, space and material; the 'speed' code determines the speed rate of works done by cloud services; the 'information literacy' code determines the effect of cloud services on information literacy; the 'storage' code determines data management systems supported by cloud services. In the personal main theme, the positive aspects are determined as " $n=20$ " for security, " $n=32$ " for flexibility, " $n=17$ " for speed, " $\mathrm{n}=46$ for information literacy and " $\mathrm{n}=34$ " for storage. In the personal main theme, the answers supporting the results are like the following;

"K34; Secure storage service and online file sharing are the important features which show that cloud system should be used."

In the professional main theme, 'teaching skills' code determines the effect of cloud services on teaching skills; the 'research skill' code determines the effect of cloud services on researching skills; the 'interaction' code determines the teacher-teacher student-teacher interaction in educational cloud environment; and these are explained by content analysis. The positive aspects are determined as " $\mathrm{n}=40$ " for teaching skill, " $\mathrm{n}=23$ " for research skill, " $\mathrm{n}=37$ " for interaction. In the main theme of professional, the answers supporting the results are like the following;

"K60; cloud services improve the teacher-students interaction. Thanks to cloud systems, teacher can create the awareness for using technology effectively. Additionally, teachers can encourage students to improve their information literacy knowledge. Thus, the communication between student and teacher improves."

\subsection{The Findings Related to the $8^{\text {th }}$ Research Question}

The codes developed by the answers given by teacher candidates are divided into 2 categories for the 8th research question: "What could be the benefits of using cloud services in terms of students?"

Table 9. Benefits of cloud services for students

\begin{tabular}{lll}
\hline Category & Main Theme & $\begin{array}{l}\text { Codes } \\
\text { Positive }\end{array}$ \\
\hline & Collaboration (p) & 40 \\
& Communication (p) & 32 \\
Pedagogical & Information literacy (p) & 8 \\
& Inquiry (p) & 6 \\
& Learning (p) & 10 \\
& Motivation (p) & 13 \\
& Participation (p) & 10 \\
& Preparation (p) & 25 \\
Technical & Reinforcement (p) & 18 \\
& Self-esteem (p) & 6 \\
& Connection (t) & 40 \\
& Cost (t) & 4 \\
& Flexibility (t) & 17 \\
& Provided space (t) & 31 \\
\hline
\end{tabular}

These categories are analyzed according to "positive" aspects and frequencies are given in Table 9. The categories are introduced as pedagogical and technical. The answers given by teacher candidates are stated numerically with the help of codes.

The 'technical' code determines the benefits of cloud services with regard to technical features; the 'pedagogical' code determines the benefits of cloud services with regard to pedagogical features in main themes. In the technical main theme, the 'cost' code determines the financial status of cloud services; the 'flexibility' code determines the independency of cloud services from time, space and material; the 'transaction speed' code determines the speed rate of works done by cloud services; the 'provided space' code determines the data management systems supported by cloud services and the 'connection' code determines the connection individuals to the same space synchronize or 
desynchronize. In the technical main theme, the positive aspects are determined as " $\mathrm{n}=4$ " for cost, " $\mathrm{n}=17$ " for flexibility, " $\mathrm{n}=17$ " for transaction speed, " $\mathrm{n}=31$ " for provided space and " $\mathrm{n}=40$ " for connection. In the technical main theme, the answers supporting the results are like the following;

"K34; cloud services allow users to make operations on shared works simultaneously and editing a file in all the environments where the internet is available (the problems caused by mobile phones or different operation systems are eliminated.)"

In the pedagogical main theme, the 'reinforcement' code determines the use of cloud services as a reinforcement for course subject after the lesson; the 'preparation' code determines the use of cloud services to prepare for course subject before the lesson; the 'communication' code determines the student-student teacher-student communication in educational cloud environment; the 'collaborative' code determines collaborative learning in groups; the 'learning' code determines the effect of cloud services on learning; the 'motivation' code determines the students' motivation among cloud service used courses; the 'inquiry' code determines the encouragement of cloud services to research; the 'information literacy' code determines the effect of cloud services on information literacy; the 'active participation' code determines the status of active participation among cloud service used courses and 'self-esteem' determines the effect of cloud services on students' self esteem and these are explained by content analysis. The positive aspects are determined as " $\mathrm{n}=18$ " for reinforcement, " $\mathrm{n}=25$ " for preparation, " $\mathrm{n}=32$ " for communication, " $\mathrm{n}=40$ " for collaborative, " $\mathrm{n}=10$ " for learning, " $\mathrm{n}=13$ " for motivation, " $\mathrm{n}=6$ " for inquiry, " $\mathrm{n}=8$ " for information literacy " $\mathrm{n}=10$ " for active participation, " $\mathrm{n}=6$ " for self-esteem. In the main theme of pedagogical, the answers supporting the results are like the following;

"K11; it increases students' attendance and improves their learning. It allows students to work collaboratively."

\subsection{The Findings Related to the $9^{\text {th }}$ Research Question}

The codes developed by the answers given by teacher candidates are divided into 3 categories for ninth research question: "In your opinion, what are the most appropriate course and subject for the use of cloud services? A. can it be used in individual or group instruction? B. is it appropriate for large populated classes?"

Table 10. Appropriateness of cloud services

\begin{tabular}{|c|c|c|c|}
\hline \multirow{2}{*}{ Category } & \multirow{2}{*}{ Main Theme } & \multicolumn{2}{|c|}{ Codes } \\
\hline & & Positive & Negative \\
\hline \multirow{4}{*}{ Courses } & All Courses (c) & 18 & - \\
\hline & Application-Project (c) & 38 & - \\
\hline & Qualitative (c) & 11 & - \\
\hline & Quantitative (c) & 1 & - \\
\hline \multirow{3}{*}{$\begin{array}{l}\text { Instructional } \\
\text { Approach }\end{array}$} & Both (I) & 54 & - \\
\hline & Group (I) & 14 & - \\
\hline & Individual (I) & 8 & - \\
\hline \multirow{4}{*}{$\begin{array}{l}\text { Large Classroom } \\
\text { Population }\end{array}$} & Attendance (L) & 3 & - \\
\hline & Communication (L) & 3 & 1 \\
\hline & Control (L) & 15 & 2 \\
\hline & Time (L) & 3 & - \\
\hline
\end{tabular}

These categories are analyzed according to "positive and negative" aspects and frequencies are given in Table 10.

Categories are introduced as course, instructional approach and large classroom population. The answers given by teacher candidates are stated numerically with the help of main and sub themes.

The 'quantitative' code determines the quantitative courses like statistics, Mathematics; the 'qualitative' code determines the qualitative courses like Foreign Language; the 'application-project' code determines the courses which need to application like Informational Technology or Science and the 'all' code determines all the courses with all subjects in courses category and these are explained by content analysis. In the category of courses, the positive aspects are determined as " $\mathrm{n}=1$ " for quantitative main theme, " $\mathrm{n}=38$ " for application-project, " $\mathrm{n}=11$ " for qualitative and " $\mathrm{n}=18$ " for all. In the category of courses, the answers supporting the results are like the following; 
"K23; I think cloud systems are appropriate for every course. Content and materials can be prepared and distributed for every subject."

The 'individual' code determines the appropriate use of cloud on individual instruction; the 'group' code determines the appropriate use of cloud on group instruction and the 'both' code determines the appropriate use of cloud on both individual and group instruction in instructional approach category and these are explained by content analysis. In the category of courses, the positive aspects are determined as " $n=8$ " for individual main theme, " $n=14$ " for group, " $\mathrm{n}=54$ " for both. In the category of instructional approach, the answers supporting the results are like the following;

"K84; ...cloud services are appropriate for both studying individually and as a group which facilitates learning. Therefore, students and also teachers can get benefits from using cloud services."

The 'communication' code determines student-student and teacher-student communication; the 'control' code determines teacher's control over class; the 'attendance' code determines the status of attendance on lecture and 'time' determines time spent on lectures supported by cloud services in large classroom population category and these are explained by content analysis. In the category of large classroom population the positive aspects are determined as " $\mathrm{n}=3$ " for communication main theme, " $\mathrm{n}=15$ " for control, " $\mathrm{n}=3$ " for attendance, and " $\mathrm{n}=3$ " for time and negative aspects are determined as " $\mathrm{n}=1$ " for communication and " $\mathrm{n}=2$ " for control. In the category of large classroom population, the answers supporting the results are like the following;

"K32; ... in large populated classrooms, teachers cannot interest in every student one by one. However, teachers can reach every student equally with cloud systems."

\section{Discussion and Suggestions}

Examining student teachers' responses to the open-ended questions according to content analysis method "whether student teachers' use cloud services in daily or professional life" has been questioned. The responses given by participants are divided into 3 categories and analyzed in terms of "positive and negative" aspects. The views of the participants are organized as the "need, knowledge, access, storage and sharing" topics in personal category; "security and internet" topics in technical category; "assignments, lecture notes and collaboration" topics in educational category. According to the results, student teachers use cloud systems for file sharing and they do not use cloud systems because they do not need them or they do not know them mostly. In the first research question the answers supporting the results are like the following;

"K1; Generally I prefer these systems for file sharing. In fact, I don't have any idea about using these systems on the purpose of education."

"K26; I don't use cloud systems and I don't have any account because I haven't needed those systems up to present."

Secondly, "the strengths and weaknesses of cloud services in education" has been questioned. The responses given by participants are divided into 3 categories and analyzed in terms of "positive and negative" aspects. The views of the participants are organized as the "responsibility, communication and knowledge" topics in personal category; "Flexibility, Time, Space, Connection, Security, Internet, System, Cost and usability" topics in technical category; "Collaboration, Feedback, Active Participation, Control and independence" topics in educational category. According to the results, cloud systems' main advantage is the flexibility of use independence from time and space and their main disadvantage are security issues and the fact that they rely on the internet connection. In fact college students tend to use flexible learning platforms that allow them learning from whenever and wherever they want (Beyth-Marom, R., Chajut, E., Roccas, S., \& Sagiv, L. 2003). Cloud servers supply that flexible environment - where innovative teaching methods can be reached by students from anywhere via tablets, computers or mobile devices (Pardeshi, V. H. 2014). Similar to our results, researchers found that adoption of cloud computing decreases with the doubt of data security and risks (Sabi, H. M., Uzoka, F. M. E., Langmia, K., \& Njeh, F. N. 2016). On the contrary, according to some studies, usage of cloud systems in education reduces risks and enhances security (Sultan, N. 2010)(Bouyer, A., \& Arasteh, B. 2014). In the second research question the answers supporting the results are like the following;

"K45; thanks to cloud systems, we can share our data with people we want and edit it collaboratively. Especially, saving and sharing oversized files are really convenient."

"K4; the data exchange rate alters depending on the internet speed which means the less internet speed the less exchange rate. Another weakness of cloud systems which concerns everybody is the security issues. There is a possibility that malicious people can seize the data saved in virtual servers." 
Thirdly, "the benefits of using cloud services for educational purposes" has been questioned. The responses given by participants are divided into 2 categories and analyzed in terms of "positive" aspects. The views of the participants are organized as the "Flexibility, Time, Space, Connection, Security, Application, Cost, usability and performance" topics in technical category; "Collaboration, Learning, Active Participation, motivation, independency, Responsibility, Communication and Information literacy" topics in educational category. According to the results, cloud systems' main benefits for educational purposes are the flexibility and cost of use, and the fact that they support connection and collaboration between different users. According to several studies, cloud systems are cost effective since they eliminate the obligation of having the latest hardware and software for institutions (Bouyer, A., \& Arasteh, B. 2014)(Pardeshi, V. H. 2014)(Sabi, H. M., Uzoka, F. M. E., Langmia, K., \& Njeh, F. N. 2016)(Koch, F., Assunção, M. D., Cardonha, C., \& Netto, M. A. 2006) (Jalali, M., Bouyer, A., Arasteh, B., \& Moloudi, M. 2013). Moreover, creating a collaborative learning platform with cloud systems reduces the gap between learner and instructor and also the work load on the instructor since students can learn from each other by the connection (Liao, J., Wang, M., Ran, W., \& Yang, S. J. 2014). In the third research question the answers supporting the results are like the following;

"K56; it is really useful in sharing data, assignment, Project and information and sending files. It is a useful platform for both students and teachers. It facilitates studying, it saves time."

"K4; especially distance education, mobile learning, collaborative learning are supported by cloud systems. We can motivate our students via using these technologies."

Fourthly, "whether participants use cloud systems for the management of classroom applications and activities or for daily interactions" has been questioned. The responses given by participants are divided into 2 categories and analyzed in terms of "daily and educational" aspects. The views of the participants are organized as the "Lecture Notes, Assignment, Document, Music, Video, Image and Applications" topics in storage/sharing category; "announcements, interaction and assistance" topics in communication category. According to the results, participants use cloud systems in daily life mostly for interaction and document storage and sharing and also they use cloud systems in educational aspect for interaction and storage and sharing lecture notes mostly. Similar to our findings, researchers observed that the most important factors are the price and storage capacity in choosing a cloud service (Burda, D., \& Teuteberg, F. 2016). In the fourth research question the answers supporting the results are like the following;

"K113; ...I use it for daily interaction usually. For example, to stay in touch with my friends, sending files or sharing photos."

"K22; I use cloud Technologies in order to share data with my friends, be in interaction with them, working collaboratively, creating a communication environment, reaching the up-to-date knowledge."

Fifthly, "the limitations of the use of cloud services in education" has been questioned. The responses given by participants are divided into 3 main themes and analyzed in terms of "negative" aspects. The views of the participants are organized as the "cost, limit, internet connection, Hardware/software, security, usability, compatibility and system" technical main theme; "recognition, Communication, Information, literacy, responsibility" topics in personal main theme; Psychomotor, affective, Learning and distraction" topics in pedagogical main theme. According to the results, participants think that the main limitations of cloud system are reliability on the internet connection and recognition of those systems by people. Indeed, if people are not aware of those systems' features they do not likely to adopt them (Sabi, H. M., Uzoka, F. M. E., Langmia, K., \& Njeh, F. N. 2016). In the fifth research question the answers supporting the results are like the following;

"K89; there are security problems because the control does not belong to the user. Moreover, availability of internet connection or the low internet speed can cause to lose the link with desired files."

"K41; ... it is not being used sufficiently because educational training is not given."

Sixthly, "whether participants use cloud systems for the management of classroom applications and activities or for daily interactions" has been questioned. The responses given by participants are divided into 2 categories and analyzed in terms of "positive" aspect. The views of the participants are organized as the "cost, flexibility, Time, Provided space, connection, usability, performance, security and compatibility" topics in technical category; "Makeup, preparation, Communication, Collaborative, learning, motivation, inquiry, Information literacy, Active participation and Responsibility" topics in pedagogical category. According to the results, participants use cloud systems in their professional lives because those systems are flexible in terms of time and space and also those systems enable connection and communication in one platform with various users. In a study conducted by 
researchers, a virtual learning environment is created with cloud technologies. The students who use those environments are satisfied with the learning experiment and it is revealed that learning environments in cloud structure meet the users' needs and maximize the benefits in learning (Hegazy, A. F., Khedr, A. E., \& Al Geddawy, Y. 2015). In the sixth research question the answers supporting the results are like the following;

"K78; ...students can reach the knowledge quickly. Students and teachers can work on the same assignments or group projects synchronously. Moreover they can share the knowledge via Office Program which means they can view their work on the browser without the need of any other software."

"K2; ...I use cloud systems. Doing so, I can stay in touch with my students every time and students can help each other and can be aware of the content everywhere and every time.

Seventhly, "the benefits the use of cloud services as a teacher candidate" has been questioned. The responses given by participants are divided into 2 main themes and analyzed in terms of "positive" aspect. The views of the participants are organized as the "Security, flexibility, speed, Information Literacy, Storage" topics in personal main theme; "Teaching skills, Research skill and Interaction" topics in professional main theme. According to the results, participants think that cloud services may have benefits on personal development of individual's information literacy knowledge and can improve teaching skills. According to a research, distance education systems based on cloud infrastructure can enhance the level of teaching by improving teaching resource utilization (Wang, Y. 2014). Moreover with the synchronous communication, teachers can guide their students in a flexible, convenient and interactive environment (Zhao, H. Y., Zhang, P., Zhang, H., \& Zhang, X. Y. 2014). In the seventh research question the answers supporting the results are like the following;

"K68; it provides for us to improve our technology-literacy to update ourselves and to create our own library with our own knowledge."

"K51; ...various teaching strategies, methods and techniques can be used and we can measure learning capabilities of students which lead us to find new teaching methods."

Eighthly, "the benefits of the use of cloud services for students" has been questioned. The responses given by participants are divided into 2 main themes and analyzed in terms of "positive" aspect. The views of the participants are organized as the "cost, flexibility, Transaction speed, Provided space, connection" topics in technical main theme; "Reinforcement, preparation, Communication, Collaborative, learning, motivation, inquiry, Information literacy, Active participation, Self-esteem" topics in pedagogical main theme. According to the results, participants think that cloud services may have benefits on connection and collaborative work with various people. In a similar study in which students' views are observed, it is revealed that in a classroom designed by cloud computing, students enjoy with informal learning and communication; their encouragement, academic engagement and individual and group learning skills are improved (Schneckenberg, D. 2014). In virtual environment based on cloud computing created for students who study in a field which requires application in real environments is more secure, cost effective and flexible environment which allows working in situations that may be impossible in reality collaboratively (Jalali, M., Bouyer, A., Arasteh, B., \& Moloudi, M. 2013). In the eight research question the answers supporting the results are like the following;

"K34; cloud services allow users to make operations on shared works simultaneously and editing a file in all the environments where the internet is available (the problems caused by mobile phones or different operation systems are eliminated.)"

"K98; ...Students can reach, edit and save their assignments via their tablets or mobile phones without the need of P.C. when they work individually or as a group.

Lastly, "the most appropriate course and subject for the use of cloud services and whether those systems are appropriate for group or individual instruction and large populated classes" has been questioned. The responses given by participants are divided into 3 categories and analyzed in terms of "positive and negative" aspects. The views of the participants are organized as the "Quantitative, Application-Project, Qualitative and All" topics in courses category; "Individual, Group and Both" topics in instructional approach category; "Communication, Control, Attendance and Time" topics in the large classroom population category. According to the results, participants think that cloud services are more appropriate for application-project courses and both for group and individual instruction. Moreover they think that controlling large populated classrooms may be easy via those services. According to researchers, academic institutions can benefit from cloud computing in administration and classroom management at minimal cost (Elamir, A. M., Jailani, N., \& Bakar, M. A. 2013). In the ninth research question the answers supporting the results are like the following; 
"K84; ...cloud services are appropriate for both studying individually and as a group which facilitates learning. Therefore, students and also teachers can get benefits from using cloud services."

"K32; ...in large populated classrooms, teachers cannot interest in every student one by one. However, teachers can reach every student equally with cloud systems."

To conclude, most of the teacher candidates who participated in this study acknowledge that using cloud services in education is efficient for 21 st century students, teachers and institutions. Although using cloud services in education may have limitations such as requiring Internet connection and data security risks, those can be eliminated or kept at minimum with a low cost.

Therefore, cloud technologies should be integrated into education and teacher candidates who will use them should be educated. If there are deficiencies in the education process of the teacher candidates, the curriculum should be planned considering those deficiencies. Thus, the knowledge and skills of the teachers who are one of the most important components of the technology integration process in education can be improved.

As some of the advantages of cloud technologies are synchronous interaction of teacher-student-environment, independency from time and space and being a technological environment which lets students to work collaboratively all the components can be configured simultaneously. Therefore, it is suggested that information technology teachers should give lectures in those environments which integrate online technologies into the learning-teaching process.

In the process of teacher candidates' integration into this technology-supported process and in gaining collaborative working habit, learning the integration of information technologies is important for using collaborative technologies in their lectures in their future professional life. Moreover, their most important duty is the integration of cloud technologies in teaching-learning process. New designed courses should be added to teacher training programs where applications related to cloud services can be done.

\section{Acknowledgement}

We would like to thank the participants in my research.

\section{References}

Al Noor, S., Mustafa, G., Chowdhury, S. A., Hossain, M. Z., \& Jaigirdar, F. T. (2010). A proposed architecture of cloud computing for education system in Bangladesh and the impact on current education system. IJCSNS International Journal of Computer Science and Network Security, 10(10), 7-13.

Al-Zoube, M., Abou El-Seoud, S., \& Wyne, M. F. (2010). Cloud computing based e-learning system. International Journal of Distance Education Technologies (IJDET), 8(2), 58-71. https:/doi.org/10.4018/jdet.2010040105.

Beyth-Marom, R., Chajut, E., Roccas, S., \& Sagiv, L. (2003). Internet-assisted versus traditional distance learning environments: factors affecting students' preferences. Computers \& Education, 41(1), 65-76. http://dx.doi.org/10.1016/S0360-1315(03)00026-5.

Bouyer, A., \& Arasteh, B. (2014). The Necessity of Using Cloud Computing In Educational System. Procedia-Social and Behavioral Sciences, 143, 581-585. https:/doi.org/10.1016/j.sbspro.2014.07.440.

Burda, D., \& Teuteberg, F. (2016). Exploring consumer preferences in cloud archiving-a student's perspective. Behaviour \& Information Technology, 35(2), 89-105. http://dx.doi.org/10.1080/0144929X.2015.1012650.

Büyüköztürk, Ş., Kılıç-Çakmak, E., Akgün, Ö. E., Karadeniz, Ş. \& Demirel, F. (2013). Scientific research methods. Ankara: Pegem Akademi.

Chandra, D. G., \& Borah, M. D. (2012). Cost benefit analysis of cloud computing in education. Computing, Communication and Applications (ICCCA), International Conference on (pp. 1-6). IEEE. https:/doi.org/10.1109/ICCCA.2012.6179142.

Creswell, J. W. \& Plano-Clark, V. L. (2007). Designing and conducting mixed methods research. Thousand Oaks, CA: Sage.

Denton, D. W. (2012). Enhancing instruction through constructivism, cooperative learning, and cloud computing. TechTrends, 56(4), 34-41. https:/doi.org/10.1007/s11528-012-0585-1.

Elamir, A. M., Jailani, N., \& Bakar, M. A. (2013). Framework and architecture for programming education environment as a cloud computing service. Procedia Technology, 11, 1299-1308. https:/doi.org/10.1016/j.protcy.2013.12.328. 
Furht, B., \& Escalante, A. (2010). Handbook of cloud computing (Vol. 3). New York: Springer. https://doi.org/10.1007/978-1-4419-6524-0

Hegazy, A. F., Khedr, A. E., \& Al Geddawy, Y. (2015). An Adaptive Framework for Applying Cloud Computing in Virtual Learning Environment at Education a Case Study of "AASTMT". Procedia Computer Science, 65, 450-458. https://doi.org/10.1016/j.procs.2015.09.121

Jalali, M., Bouyer, A., Arasteh, B., \& Moloudi, M. (2013). The effect of cloud computing technology in personalization and education improvements and its challenges. Procedia-Social and Behavioral Sciences, 83, 655-658. doi:10.1016/j.sbspro.2013.06.124.

Koch, F., Assunção, M. D., Cardonha, C., \& Netto, M. A. (2016). Optimising resource costs of cloud computing for education. Future Generation Computer Systems, 55, 473-479. http://dx.doi.org/10.1016/j.future.2015.03.013.

Liao, J., Wang, M., Ran, W., \& Yang, S. J. (2014). Collaborative cloud: a new model for e-learning. Innovations in Education and Teaching International, 51(3), 338-351. http://dx.doi.org/10.1080/14703297.2013.791554.

Miles, M. B. \& Huberman, A. M. (1994). Qualitative data analysis: An expanded sourcebook (2nd edition). Thousand Oaks, California: SAGE.

Mutlu, A. P. (2015). Use as a personal learning environment in cloud-based applications. Journal of Research in Education and Teaching, 4(3), 118-124.

Özdemir, O., \& Erdemci H. (2014). Opinions of High School Vocational Students about the Use of Cloud Technologies for Homework Purposes. Turkish Journal of Educational Studies, 1(3).

Pardeshi, V. H. (2014). Cloud computing for higher education institutes: architecture, strategy and recommendations for effective adaptation. Procedia Economics and Finance, 11, 589-599. http://dx.doi.org/10.1016/S2212-5671(14)00224-X.

Piotrowski, D. M. (2013). Cloud Computing as Network Environment in Students Work. In The 21st International BOBCATSSS Conference (p. 211). ISSN: 1302-3217.

Rao, N. M., Sasidhar, C., \& Kumar, V. S. (2012). Cloud computing through mobile-learning. Computers and Society. arXiv preprint arXiv:1204.1594.

Sabi, H. M., Uzoka, F. M. E., Langmia, K., \& Njeh, F. N. (2016). Conceptualizing a model for adoption of cloud computing in education. International Journal of Information Management, 36(2), 183-191. http://dx.doi.org/10.1016/j.ijinfomgt.2015.11.010.

Schneckenberg, D. (2014). Easy, collaborative and engaging-the use of cloud computing in the design of management classrooms. Educational Research, http://dx.doi.org/10.1080/00131881.2014.965569.

Sclater, N. (2012). E-Learning in the Cloud. International Journal of Virtual and Personal Learning Environments, 1(1), 10-19. ISBN 978-1-4666-1770-4. https://doi.org/10.4018/jvple.2010091702

Şimşek, H., \& Yıldırım, A. (2011). Qualitative research methods in the social sciences. Ankara: Seçkin Yayıncılık.

Strauss, A. L., \& Corbin, J. (1998). Basics of qualitative research techniques and procedures for developing grounded theory. Thousand Oaks, CA: Sage.

Sultan, N. (2010). Cloud computing for education: A new dawn? International Journal of Information Management, 30(2), 109-116. http://dx.doi.org/10.1016/j.ijinfomgt.2009.09.004.

Tara S. Behrend, Eric N. Wiebe, Jennifer E. London \& Emily C. Johnson (2011). Cloud computing adoption and usage in community colleges, Behaviour \& Information Technology, 30(2), 231-240. https:/doi.org/10.1080/0144929X.2010.489118

Wang, Y. (2014). The Study of Distance Education System Based on Cloud Computing and Resource Integration. In Applied Mechanics and Materials (Vol. 687, pp. 2841-2844). Trans Tech Publications. https:/doi.org/10.4028/www.scientific.net/AMM.687-691.2841.

Zhao, H. Y., Zhang, P., Zhang, H., \& Zhang, X. Y. (2014). Building distance education system based on cloud computing. In Applied Mechanics and Materials (Vol. 513, pp. 510-513). Trans Tech Publications. https:/doi.org/10.4028/www.scientific.net/AMM.513-517.510. 